\title{
Exploring the Digital Age: The Carrying Capacity of Virtual Reality Technology for Historical and Cultural Heritage
}

\author{
Sizhe $\mathrm{Li}^{1,{ }^{1}}$ \\ ${ }^{1}$ University College of London, Institution Of Education, UK London \\ *Corresponding author. Email: sizhe.li.20@ucl.ac.uk
}

\begin{abstract}
This paper discusses the role and influence of virtual reality (VR) technology on historical and cultural inheritance under the background of the digital age. The essential feature of VR is to enhance users' perceptions and experiences by immersing users in the virtual world. It greatly promotes the democratic text of cultural heritage and describes the advantages of this new technology in preserving and providing new forms of cultural heritage access. The advantages of this emerging technology in preserving and providing new forms of cultural heritage access are also described. This paper will be of interest to scholars and institutions considering the use of VR technologies to support cultural heritage conservation, digital humanities projects or other types of interdisciplinary research.
\end{abstract}

Keywords : Virtual Reality (VR), history culture, cultural heritage, digital media

\section{INTRODUCTION}

In the past decade, the number of digital media projects on various scales has increased dramatically in various heritage environments around the world [1]. Digital media is encoded in digital format, which is usually transmitted and presented on electronic devices [2]. Modern digital systems and resources are promoting a new understanding of cultural heritage, with a variety of information resources [4].

VR technology is an important representative of digital media. It is an alternative world, full of computer-generated images that respond to human actions. VR technology provides an unprecedented user experience in 3D visualization, which shows great potential for the presentation of history and culture. VR makes users feel that they exist in the rendered immaterial world. This immersion is mainly realized through the combination of vision and sound. The virtual environment is used to let the experiencer interact with a place, person or object, where they should experience the feeling of "being there", also known as being. The two important factors that affect the sense of existence are immersion and interaction, which means that the combination of information and images that can be operated by users interactively and immersive experience are the two basic advantages of virtual reality technology: users can experience the feeling and cultural atmosphere of the ancient world and actively participate in the interaction between virtual environment and cultural relics and space. In this direction, the visualization of virtual environment of cultural heritage can enrich and supplement but cannot completely replace the access and experience of spatial location [5]. Digital media plays an increasingly essential role in heritage protection, constantly revising and broadening our feelings and cognition of time and space. On the one hand, it can complete the information storage and protection of cultural heritage; on the other hand, it can also repair and reproduce cultural heritage through multi-dimensional and interactive virtual information platforms [10].

Historically, the concept of cultural value of heritage was mostly determined by experts in institutions with a large number of cultural relics [1]. The advent of the digital age has reversed the pattern of non-democratic one-way cultural communication. Enhancing positive two-way communication with heritage provides the potential for promoting access [14]. We see digital space as a way of physical interaction and a new opportunity to gain another emotional experience. There is no binary opposition between the real object and its digital representation. They complement each other, that 
is, "an alternative reciprocity model interacting with things" [1].

The core question that drives my research is what role virtual reality technology plays in historical and cultural inheritance in the digital era and what the relationship between them is. In view of this problem, this paper will discuss the potential of digital VR in influencing historical and cultural heritage and what role culture plays in VR. The following five directions will be discussed:

- Cultural value orientation: the importance of historical and cultural heritage and transmission bias in the digital age.

- The value of digital experience: two-way communication and digital retrieval of Digital Heritage.

- Immersion and interaction: the influence of VR perception on Cultural Heritage.

- Restoration and preservation of historical and cultural heritage: the digital preservation and restoration of cultural heritage are easier to establish systematic standards, and the restoration based on it becomes more potential.

- The value of space-time: the dependence of digital cultural heritage on space and time and the display of historical significance behind Heritage.

\section{CULTURAL VALUE ORIENTATION}

According to ICOMOS (2002), cultural heritage includes customs, places, objects, artistic forms and values. Cultural heritage is usually divided into intangible cultural heritage and tangible cultural heritage. These include tangible culture (e.g., buildings, monuments, landscapes, books, works of art and artefacts), intangible culture (e.g., folklore, tradition, language and knowledge) and natural heritage (e.g., landscapes and biodiversity of cultural significance). As an important carrier of culture, cultural heritage has passed down culture from the long river of history. They are not only the identity symbol of regional culture, that is, the sense of belonging, but also have great significance to the cultural diversity of the world [6]. Digital technology is likely to provide us with new insights into our understanding of the past, so as to make us a part of society with a wider scope of application [1]. As a medium or tool, digital media can be better combined with cultural symbols to produce creative communication significance [14].

Alberto Acerbi (2016) argued that history and culture will spread in digital media through the perspective of cultural communication bias. In other words, digital media will expand the transmission bias. Digital media such as VR can accurately locate and quantify the popularity of certain cultural heritages, and those cultural heritages with high popularity will get more access and exploration [2]. On the contrary, cultural heritages that are not popular may receive less attention and spread, and VR can still selectively expose and inherit them through preservation and restoration [6]. Therefore, cultural evolution will provide a privileged perspective to examine digital media. However, some different voices in the academic circles are also worth noting. Laura et al. (2016) think that digital tools will reduce the intrinsic cultural value of cultural relics, which corresponds to what Povroznik (2018) mentions attention deprivation. We should avoid that digital visualization excessively deprives the experience of the culture itself [3], but this also shows the tension of digital VR on the cultural load.

\subsection{The value of digital experience}

The field of digital culture under the combination of VR is two-way, which can provide a dynamic space for two-way communication with traditional culture [1]. In this two-way information transmission process, the author and the experiencer are not antagonistic, and the interface boundary between them is more and more blurred [14]. Part of the power of the curator is transferred to the participants, who are free to choose the content to visit. Besides, digital methods can jointly produce exhibitions, oral history and other forms of exhibitions and archives based on personal memory, recall and interactivity, which means that it also encourages participants to invest in knowledge creation. This allows the participants to use and reinterpret the value of cultural heritage, thus promoting the generation of a new depth of participation and cultural value. This is the phenomenon of information democratization in the digital age [1].

VR is a powerful model to explore the 3D content of cultural heritage, and its combined cultural heritage has great potential in the field of cultural utilization of education and research. High fidelity visual resources can be integrated and put into retrieval [3]. In addition, digital heritage combined with VR can also transfer intangible parts of culture, including feeling, perception, motivation, and motivation, so as to express the emotion behind historical relics [7]. Besides, through the combination of object and public image, the inner cultural attribute of the exhibits is fully conveyed, and the function of cultural education and communication is played. Participants can experience all the information of the exhibits through the most intuitive senses, which greatly meets the emotional needs of people [12].

\subsection{Immersion and interaction}

Any cultural perception depends on the physical experiences, so it is very important to pay attention to the influence of physical perception. Immersive and 
interactive experiences can promote the historical and cultural heritage to the level of behavioural perception through putting the experiencers in the immersive cultural visualization and transferring the cultural perception to them [9]. As Khosrow (2020) said, in the VR cultural experience, the system must be credible for the experiencer, which means that it can feel as if they are really there. It can be interactive and be explorable when the users reach out their arms. In the interactive and immersive environment, users can learn and experience, and help them further integrate into the virtual world and stop the feeling of distrust [4]. When people are completely immersed in it, they will enter the subjective state of "flow", in which they forget time, fatigue and everything except the activity itself [13]. It is this flow state that can greatly improve the cultural perception and memory efficiency of the experiencer, which is undoubtedly beneficial to the inheritance of history and culture.

Interaction is a kind of behavior design. The audience plays the role of the aesthetic subject in the process of interactive experience, and constantly meets their own psychological needs of art, aesthetics, emotion, and self-realization. The interactive experience between users and cultural heritage in virtual space is a complex and high-level spiritual activity, which is constantly changing and developing under the interaction of users' consciousness and subconsciousness, subjectivity and rationality, intuition and logic. When participating in interactive behavior, users develop from instinct level to reflection level, resulting in emotional and psychological changes, and ultimately affect their aesthetic experience [9]. Interaction makes participants change from passive acceptance in traditional media to active participation and become participants. The use of interactive means expands its development space [12].

Through the VR perception, intangible cultural concepts will be visualized, which brings more layers of interpretation to culture. This is a new dimension connected with history and culture [1]. Through this dimension, they can more easily achieve their goals which can be set by the creators of virtual environments, so that they are constructive and helpful in various fields [4].

Digital experience with immersion and interactivity can make the body of the experimenter excited again. In other words, "digital-driven physical interaction", which means the online interaction of experiencers promotes the frequency of users' access to cultural entities [1]. From this point of view, the perception of VR greatly enhances the carrying capacity of history and culture, spiritually and physically.

\subsection{Restoration and preservation of historical and cultural heritage}

Zhang (2021) believes that accurate and detailed preservation and recording of historical heritage based on digital technology can protect data more easily from loss and damage, and VR-based cultural visualization preservation can customize unified technical application standards and data formats to achieve efficient and standardized digital system management [8]. On the basis of this detailed data preservation, the restoration and display of cultural relics that are disappearing or have disappeared regardless of man-made or natural factors will become rule-based. Moreover, the integrated information resource system can be retrieved and displayed more orderly and easily, which is conducive to the field of education and research. People in educational research communities around the world can use data anytime and anywhere on the Internet for their educational research purposes [3]. However, Khosrow (2020) puts forward different opinions. He thinks that VR also increases the complexity of preservation. There are problems in the long-term preservation and sustainability of the integrated system; so, the original digital production sequence has to be preserved to make the context researchable. Sorting and storage of a large amount of data is a complex problem. With the development of technologies, this problem will be solved gradually [4].

In addition, VR technology can break through the limitation of time and space and make full use of the value of cultural relics. The collected data and information, archaeological research data, and literature records will be collected to simulate the display of sites and remains that have not been excavated or have been annihilated, so as to promote the development and dissemination of historical relics from multiple perspectives [11]. This means that it cannot only expand the display space [1], but also reduce the risk in collection and display [5]. For the former, some of the exhibits that are inconvenient to display in reality are easily damaged by natural wind, rain or light for a long time, and some of the details of the exhibits have been eroded and disappeared [1]. For the latter, the internal security of some architectural and cultural heritages is not enough to allow people to physically exam, and many cultural heritages are still in the area of war and cannot be accessible to the public. [5]. These problems have been solved to a certain extent after combining with the VR technology.

Taking the Mogao Grottoes in Dunhuang as an example, the Mogao Grottoes in Dunhuang have a special geographical location and have been faced with problems such as wind erosion, water seepage and man-made destruction for a long time. Once the cultural relics of Mogao Grottoes are damaged, which will cause permanent losses. Therefore, Dunhuang Research 
Institute and Northwest University have cooperated to adopt two technical means: covering photography technology and VR technology. Those two ways can help shoot high-resolution images and make cave virtual models. The researchers from those two institutions can view the scenery of the cave in all kinds of use scenes and interact with the cultural relics (e.g., murals and collections) in the scene, without being limited by geographical locations and other factors. It shows that under the background of digital technology, the preservation of cultural heritage brings visitors a more uncertain and pleasant aesthetic experience [9]. Another example is that a large-scale historical landmark in Kerman, Iran's desert city, the Gangali Khan building complex, is under the pressure of geopolitics and war. Researchers use a 3D VR technology to show the interior and exterior architectural details and structure principles in a multi-sensory dimension for people to visit. This not only protects the cultural heritage in the war, but also provides more people in the world with the opportunity to visit and appreciate the architectural value and the cultural value behind the Ganjiali complex. This also plays a key role in the protection of national culture endangered in the war [4].

\section{THE VALUE OF SPACE-TIME}

Laur (2016) and others found that although the boundaries between the physical world and the online world become more and more blurred, the physical sense of place will not disappear. In other words, people's learning of the cultural value of heritage still needs the assistance of spatial location, and their perception of culture will be better in museums and other locations. This is a good suggestion for the presentation of VR. In the modeling of virtual space, we should pay attention to the cultural value in the place. Digital tools should enhance rather than replace the position of objects [1].

Drossis (2018) and others believe that the understanding of historical relics is often limited by time in reality, but the lack of thinking time and feeling time can be alleviated by VR visualization and interactive immersion [5]. Participants can be repeatedly exposed to VR visual virtual scenes with appropriate visual and auditory assistance.

VR helps to explore the history and significance behind cultural heritage. Through the visualization of the virtual scene, the historical context of cultural heritage (largely invisible) can be displayed in the form of vision and hearing [11]. This shows that digital media and cultural information are not binary opposites, they are integrated with each other [1], creative development [8]. However, unlike the VR mentioned above, they will bring more two-way interaction and accelerate the democratic dissemination of culture. Povroznik (2018) believes that the visualization under this fusion will just block the Democratic dissemination of information resources, cut off the audience's free imagination and ossify the imagination of cultural content, which is deepened with the improvement of immersion [3].

\section{CONCLUSION}

In the new digital era, historical and cultural inheritance needs to change the rigid concept that only traditional means can be used to inherit culture. It can provide more ideas for the development and spread of cultural heritage. Culture and science and technology interact with each other. People should not regard them as binary opposites. Science and technology and culture have two-way interaction. This requires scholars to pay attention to the external forms of VR culture and pay more attention to people's spiritual needs and aesthetic experience. Only in this way can science and technology be better combined with humanities, and the democratization of information and access be promoted.

In the process of cultural heritage protection and storage, VR visualization of cultural heritage can shorten the distance between cultural heritage and the digital deduction process, and constantly enhance the public's feelings and cognition of material cultural heritage. At the same time, the digital media technology and related hardware and software facilities have promoted the development of digital cultural heritage to a certain extent, which can effectively preserve the material cultural heritage, expand and extend in the process of communication and exchange with the help of digital media in various forms, so as to realize the social value, historical value and artistic value of the material cultural heritage Multiple inheritance of value. Therefore, digital archiving is the basis for the inheritance of cultural heritage. Digital protection and restoration reappear the glory of cultural heritage.

Back to central question that what role virtual reality technology plays in the historical and cultural heritage in the digital age and what the relationship is, the forefront of exploring digital possibilities in heritage is now widely recognized in the field of practice. The integration of VR and cultural heritage promotes the democratization of information access and creation in cultural communication. From the perspective of history and culture, the interaction between history and culture is accelerated. In addition, through VR experience, the cultural relics are displayed in front of the experiencers, which is helpful to reveal and understand the cultural significance behind the cultural relics. In the digital era, VR-based cultural visualization preservation can customize unified technical application standards and data formats to achieve efficient and standardized digital system management, which is good news for scholars in all related fields of society, increasing the standard, integrity and speed of historical and cultural communication. From this point of view, as a digital 
media, VR has a huge carrying capacity for historical and cultural heritage. The two complement each other and promote each other.

\section{AUTHORS' CONTRIBUTIONS}

This paper is independently completed by Sizhe Li.

\section{ACKNOWLEDGMENTS}

Many people have given me valuable help in my essay writing, including my tutor, my friends and my parents. First of all, I would like to express my heartfelt thanks to Professor Sunglim Kim for giving me the course of art history and bringing me more critical thinking. I also sincerely thank my assistant and friend Chi Chenkai, who has given me great help and provided me with the necessary information and suggestions. These information and suggestions are of great value and inspiration to my essay ideas and research. With his advice and help, I have deeper thinking about cultural values. Here, I am very happy to thank my thesis writing teacher Jiaqiong Sun for her help in writing this thesis. Finally, I would like to thank my parents for their financial and spiritual support. They have given me enough choice space to freely choose what I want to pursue. This is very helpful for me to finish this essay successfully.

\section{REFERENCES}

[1] King, Laura, Stark, James F, and Cooke, Paul. Experiencing the Digital World: The Cultural Value of Digital Engagement with Heritage. Heritage \& Society 9.1 (2016): 76-101. Web.

[2] Acerbi, A. A Cultural Evolution Approach to Digital Media. Frontiers in Human Neuroscience 10. 2016 (2016): 1-12. Web.

[3] Povroznik, Nadezhda. Virtual Museums and Cultural Heritage: Challenges and Solutions. DHN. 2018.

[4] Bozorgi, Khosrow, and Lischer-Katz, Zack. Using 3D/VR for Research and Cultural Heritage Preservation: Project Update on the Virtual Ganjali Khan Project. Preservation, Digital Technology \& Culture 49.2 (2020): 45-57. Web.

[5] Drossis, Giannis, Chryssi Birliraki, and Constantine Stephanidis. Interaction with immersive cultural heritage environments using virtual reality technologies. International Conference on Human-Computer Interaction. Springer, Cham, 2018.

[6] Druk gi Chokey. Cultural Heritage, Importance of Cultural Heritage. 2016. Web.

[7] Selmanović, Elmedin, et al. Improving accessibility to intangible cultural heritage preservation using virtual reality. Journal on Computing and Cultural Heritage (JOCCH) 13.2 (2020): 1-19.

[8] Zhang Ruifeng. Digital protection of architectural cultural heritage. Urban housing 28.02 (2021): 192-193 doi:CNKI : SUN:CSZZ.0.2021-02-064.

[9] Xu Yingyan. Research on the application of interactive virtual display design in cultural heritage -- a case study of Mogao Grottoes. Art education research. 03 (2021): 44-45 doi:CNKI : SUN:MSJY.0.2021-03-025.

[10] Zhou Jie. The role of digital media art in the protection of material cultural heritage. Art grand view. 04 (2021): 137-138 doi:CNKI : SUN:YSDG.0.2021-04-070.

[11] Zara, J. Virtual reality and cultural heritage on the web. In Proceedings of the 7th International Conference on Computer Graphics and Artificial Intelligence (Vol. 330), 2004, (5).

[12] Wu Yang. Exploration and development of digital virtual technology in the restoration of ancient buildings. Art science and technology 29.11 (2016): 38 doi:CNKI : SUN:YSKK.0.2016-11-030.

[13] Csikszentmihalyi, Mihaly, Sami Abuhamdeh, and Jeanne Nakamura. "Flow." Flow and the foundations of positive psychology. Springer, Dordrecht, 2014. 227-238.

[14] Zics, Brigitta, Brigitta. Zic, and Magyar Képzőmüvészeti Egyetem. The Transparent Act / Brigitta Zics. 2018. Print. 